\title{
ESTIMASI NILAI RIPITABILITAS BOBOT SAPIH DAN MOST PROBABLE PRODUCING ABILITY KAMBING SABURAI BETINA DI KECAMATAN SUMBEREJO, GISTING, DAN KOTA AGUNG TIMUR KABUPATEN TANGGAMUS
}

\author{
Estimation of Repeatability Value and Most Probable Producing Ability of Weaning Weight of Female \\ Saburai Goat in Sumberejo, Gisting and East Kota Agung District, Tanggamus Regency
}

Ibrahim Ikhlas Saputra, Sulastri, Muhammad Dima Iqbal Hamdani, dan Akhmad Dakhlan

Departement of Animal Husbandry, Faculty of Agriculture, University of Lampung

Jl. Prof. Dr. Soemantri Brojonegoro No.1 Gedung Meneng Bandar Lampung 35145

e-mail : ikhlassaputraibrahim@yahoo.com

\begin{abstract}
The research was conducted with the aim of knowing the repeatability estimate and Most Probable Producing Ability (MPPA) value of the weaning weight of female Saburai goats. This research was conducted from July to September 2019 in Gisting, Sumberejo, and East Kota Agung districts, Tanggamus regency, which is the development area for Saburai goat seeds. This research used a survey method. The data used was in the form of primary data obtained from breeders through questionnaires and secondary data, namely in the form of farmer's goat records. The research material consisted of recording of female Saburai goats which had given birth more than twice. The records required in this study included age of dam at delivery, age of kid at weaning (weaning age), kid's birth weight, weaning weight of the kid, type of birth, and sex from 2016 to 2018, and questionnaires for breeders. The results of this study indicated that repeatability estimate of weaning weight of Saburai goat in Gisting, Sumberejo, and East Kota Agung districts were 0.478 (high category), 0.19 (low category) and 0.13 (low category), respectively. The results also indicated that the average MPPA value of weaning weight for Saburai goats in Gisting, Sumberejo, and East Kota Agung districts were $21.91 \pm 0.04,17.91 \pm 0.06$, and $9.88 \pm 0.01$, respectively.
\end{abstract}

Keywords: Most probable producing ability, Repeatability estimate, Saburai goat

\begin{abstract}
ABSTRAK
Penelitian ini bertujuan untuk mengetahui nilai estimasi ripitabilitas dan nilai MPPA bobot sapih kambing Saburai betina di Kabupaten Tanggamus. Penelitian ini dilaksanakan di wilayah Kabupaten Tanggamus, pada Juli 2019--September 2019. Penelitian ini menggunakan metode survei. Data yang digunakan berupa data primer yang diperoleh dari peternak melalui kuesioner dan data sekunder yaitu berupa rekording kambing milik peternak. Materi penelitian terdiri dari rekording kambing Saburai betina yang sudah beranak lebih dari dua kali. Catatan yang diperlukan meliputi umur induk pada waktu melahirkan, umur anak waktu disapih (umur sapih), bobot lahir anak, bobot sapih anak, tipe kelahiran anak, dan jenis kelamin anak dari induk-induk yang melahirkan mulai 2016--2018, dan kuesioner untuk peternak. Hasil penelitian ini menunjukkan bahwa nilai ripitabilitas kambing Saburai di Kecamatan Gisting sebesar 0,478 (kategori tinggi), di Kecamatan Sumberejo sebesar 0,19 (kategori rendah), dan di Kecamatan Kota Agung Timur sebesar 0,13 (kategori rendah). Hasil penelitian juga menunjukkan bahwa rata-rata nilai MPPA bobot sapih

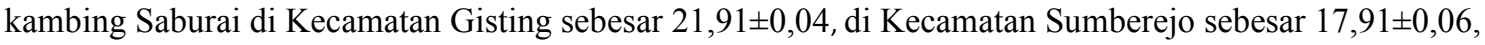

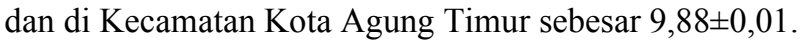

Kata kunci: Kambing Saburai, Most Probable Producing Abality, Nilai Ripitabilitas

\section{PENDAHULUAN}

Populasi kambing di Indonesia pada 2016 mencapai 19.608.181 ekor, sebanyak 57,12\% terdapat di Pulau Jawa dan sisanya tersebar di luar Pulau Jawa antara lain di Provinsi Lampung.
Provinsi Lampung merupakan provinsi dengan populasi kambing tertinggi dibandingkan dengan wilayah lain di luar (Badan Pusat Statistik, 2017).

Kambing Saburai merupakan kambing tipe pedaging hasil persilangan secara grading up antara kambing Boer jantan dengan kambing 
Peranakan Etawah (PE) betina yang ditetapkan sebagai sumberdaya genetik lokal Provinsi Lampung berdasarkan Keputusan Menteri Pertanian Republik Indonesia Nomor 359/Kpts/PK.040/6/2015

$$
\text { Upaya yang ditempuh adalah }
$$
meningkatkan populasi dan mutu genetik kambing Saburai di wilayah tersebut serta melakukan uji performa secara teratur. Kelemahan uji performa adalah tidak mempertimbangkan potensi genetik melalui estimasi parameter genetik. Individu dengan performa yang tinggi belum tentu dapat mewariskan keunggulannya pada generasi keturunannya karena performa yang tinggi mungkin bukan karena pengaruh faktor genetik tetapi faktor lingkungan (Sulastri dan Sukur, 2015).

Pemilihan individu-individu untuk dipertahankan dalam populasi seharusnya dilakukan dengan melakukan estimasi parameter genetik terhadap performa yang akan ditingkatkan dalam populasi. Berdasarkan hasil estimasi parameter genetik tersebut dapat ditentukan sistem pemuliabiakan yang tepat. Seleksi dapat ditempuh apabila parameter genetik berkisar antara sedang sampai tinggi $(>0,40-1,00)$ (Sulastri et al., 2016).

Parameter genetik merupakan nilai yang menunjukkan potensi genetik suatu performa dalam populasi. Ripitabilitas merupakan salah satu parameter genetik yang menunjukkan kemampuan individu dalam mengulang performanya pada periode yang akan datang. Nilai ripitabilitas biasanya digunakan dalam menduga keragaman genetik populasi ternak betina karena ternak betina seringkali mengulang performanya pada periode berikutnya, misalnya bobot sapih anak pada tiap paritas (Hardjosubroto, 1994).

Nilai ripitabilitas merupakan bagian dari keragaman fenotipik yang disebabkan oleh keragaman genetik total dan keragaman lingkungan permanen. Nilai ripitabilitas bukan konstanta tetapi selalu mengalami perubahan karena adanya pemasukan atau pengeluaran ternak dari dan ke dalam populasi, kelahiran, dan kematian yang mengubah frekuensi genetik (Falconer dan Mackay, 1996)

Nilai ripitabilitas digunakan dalam penghitungan nilai most probable producing ability (MPPA). Estimasi nilai MPPA digunakan dalam seleksi ternak betina untuk dikembangbiakkan dalam populasi. Seleksi pada kambing tipe pedaging bertujuan untuk meningkatkan pertumbuhan generasi keturunannya.
Berdasarkan kenyataan bahwa populasi kambing Saburai selalu mengalami perubahan akibat adanya mutasi keluar dan masuk serta adanya kelahiran dan kematian, maka ripitabilitas harus diestimasi secara periodik agar menjadi nilai yang akurat bila digunakan dalam rumusrumus pemuliaan, antara lain dalam nilai MPPA. Penelitian ini dilakukan untuk melakukan estimasi ripitabilitas dan nilai MPPA bobot sapih pada kambing Saburai di Kabupaten Tanggamus.

\section{MATERI DAN METODE}

\section{Materi}

Materi penelitian terdiri dari rekording kambing Saburai betina yang sudah beranak lebih dari dua kali. Catatan yang diperlukan meliputi umur induk pada waktu melahirkan, umur anak waktu disapih (umur sapih), bobot lahir anak, bobot sapih anak, tipe kelahiran anak, dan jenis kelamin anak dari induk-induk yang melahirkan mulai 2016 sampai dengan 2018, dan kuesioner untuk peternak.

\section{Metode}

Penelitian ini menggunakan metode survei. Data yang digunakan berupa data primer yang diperoleh dari peternak melalui kuesioner dan data sekunder yaitu berupa rekording kambing milik peternak. Pengamatan dilakukan terhadap seluruh kambing Saburai betina yang sudah melahirkan lebih dari dua kali. Batasan yang digunakan dalam penentuan individu yang diamati.

\section{Peubah yang diamati}

\section{Bobot sapih terkoreksi}

Data bobot sapih terkoreksi dihitung dengan rumus-rumus sesuai rekomendasi Hardjosubroto (1994) sebagai berikut:

$B S T=\left(B L+\left\langle\frac{B S-B L}{U S} x 120\right\rangle(F K J K)(F K T L)(F K U I)\right.$

Keterangan:

$\mathrm{BST}=$ bobot sapih terkoreksi

$\mathrm{BL}=$ bobot lahir $(\mathrm{kg})$

$\mathrm{BS}=$ bobot sapih $(\mathrm{kg})$

$\mathrm{US}=$ umur sapih (hari)

$\mathrm{FKJK}=$ faktor koreksi jenis kelamin

$\mathrm{FKTL}=$ faktor koreksi tipe kelahiran

FKUI $=$ faktor koreksi umur induk 
2. Estimasi nilai ripitabilitas

Ripitabilitas bobot sapih diestimasi untuk masing-masing populasi kambing di Kecamatan Sumberejo, Gisting, dan Kotaagung Timur. Bobot sapih terkoreksi digunakan untuk estimasi ripitabilitas dengan metode korelasi dalam kelas (intraclass correlation) sesuai rekomendasi Becker (1992).

$$
r=\frac{\sigma_{\mathrm{w}}^{2}}{\sigma_{\mathrm{w}}^{2}+\sigma_{\mathrm{e}}^{2}}
$$

Keterangan:

$\mathrm{r}=$ nilai ripitabilitas

$\sigma_{\mathrm{w}}^{2}=$ keragaman genetik total dan lingkungan permanen antarindividu dalam populasi

$\sigma_{\mathrm{e}}^{2}=$ keragaman lingkungan temporer

\section{MPPA}

Nilai MPPA bobot sapih dihitung dengan rumus sesuai rekomendasi Hardjosubroto (1994) sebagai berikut:

$$
\mathrm{MPPA}=\frac{\mathrm{nr}}{1+(\mathrm{n}-1) \mathrm{r}}(\overline{\mathrm{P}}-\overline{\overline{\mathrm{P}}})+\overline{\overline{\mathrm{P}}}
$$

Keterangan:

$$
\begin{array}{ll}
\text { MPPA } & =\text { Most Probable Producing Ability } \\
& (\mathrm{kg}) \\
\mathrm{n} & =\text { jumlah paritas per induk } \\
\mathrm{r} & =\text { ripitabilitas bobot sapih } \\
\overline{\mathrm{P}} & =\text { rata-rata bobot sapih cempe per } \\
& \text { induk }(\mathrm{kg}) \\
\overline{\overline{\mathrm{P}}} & =\text { rata-rata bobot sapih seluruh anak. }
\end{array}
$$

\section{HASIL DAN PEMBAHASAN}

\section{Gambaran Umum Lokasi Penelitian}

Kabupaten Tanggamus merupakan salah satu dari lima belas kabupaten/kota yang ada pada Pemerintahan Provinsi Lampung. Secara administratif letak geografis Kabupaten Tanggamus dibatasi oleh tiga wilayah daratan dan satu wilayah laut pada sisi-sisinya. Batas wilayah Kabupaten Tanggamus sebagai berikut: berbatasan dengan Kabupaten Lampung Barat, sebelah selatan berbatasan dengan Samudera Indonesia. Sebelah timur wilayah berbatasan dengan Kabupaten Pringsewu, sebelah utara berbatasan dengan Kabupaten Lampung Barat dan Lampung Tengah. Ibu Kota Kabupaten Tanggamus terletak tepat di tengah-tengah Kabupaten Tanggamus yaitu di wilayah Kecamatan Kota Agung Timur (Pemerintah Kabupaten Tanggamus, 2016).
Secara geografis letak Kabupaten Tanggamus berada pada $104^{\circ} 18^{\prime}$ sampai dengan $105^{\circ} 12^{\prime}$ Bujur Timur dan $5^{\circ} 05^{\prime}$ sampai dengan $5^{\circ} 56^{\prime}$ Lintang Selatan. Keempat koordinat bujur dan lintang tersebut membatasi wilayah seluas $2.855,46 \mathrm{~km}^{2}$ untuk luas daratan ditambah dengan luas wilayah laut $1.799,5 \mathrm{~km}^{2}$ luas keseluruhan sebesar 4.654,96 $\mathrm{km}^{2}$ dengan jumlah penduduk 560.286 jiwa (Pemerintah Kabupaten Tanggamus, 2016).

Kecamatan Gisting memiliki 9 desa atau pekon. Desa-desa yang ada di Kecamatan Gisting yaitu Gisting Atas, Gisting Bawah, Purwodadi, Kuta Dalom, Banjarmanis, Campang, Sidokaton, Landbaw, dan Gisting Permai. Secara administratif Kecamatan Gisting memiliki batasbatas wilayah sebagai berikut

1. Sebelah utara berbatasan dengan Kecamatan Limau;

2. Sebelah selatan berbatasan dengan Kecamatan Sumberejo;

3. Sebelah barat berbatasan dengan Kecamatan Kota Agung Timur;

4. Sebelah timur berbatasan dengan Kecamatan Gunung Alip.

5. Kecamatan Sumberejo adalah salah satu dari 20 kecamatan yang ada di Kabupaten Tanggamus. Kecamatan Sumberejo memiliki 13 desa atau pekon.

Secara administratif kecamatan Sumberejo memliki batas-batas wilayah sebagai berikut:

1. Sebelah utara berbatasan dengan Kecamatan Pulau Panggung;

2. Sebelah selatan berbatasan dengan Hutan lindung;

3. Sebelah barat berbatasan dengan Kecamatan Pulau Panggung;

4. Sebelah timur berbatasan dengan Kecamatan Gisting.

Kecamatan Sumberejo dan Kecamatan Gisting merupakan daerah dataran tinggi dengan kisaran suhu $20,8^{\circ} \mathrm{C}-22,5^{\circ} \mathrm{C}$. Pada suhu tersebut Kabupaten Tanggamus memiliki potensi besar dalam hijauan pakan ternak guna mendorong pemerintah daerah untuk mengembangkan sektor peternakan. Peternak mampu menanam rumput dan berbagai jenis legum untuk memenuhi kebutuhan pakan ternak.

Pemerintah Kabupaten Tanggamus melakukan pengembangan rumpun Kambing Saburai di Kecamatan Sumberejo dan Kecamatan Gisting. Dua wilayah tersebut dinyatakan sebagai village breeding centre atau pusat pembibitan ternak wilayah desa (Sulastri dan Qisthon, 2007) dan kini dinamakan sebagai wilayah sumber bibit kambing Saburai (Disnakkeswan Provinsi Lampung, 2015). 


\section{Manajemen Pemeliharaan Kambing Saburai}

Kandang yang berada di Kecamatan Gisting, Kota Agung Timur dan Sumberejo menggunakan kandang panggung dengan alas berupa kayu. Kandang panggung ini memudahkan peternak saat membersihkan kotoran kambing. Kandang panggung juga akan membuat ternak lebih nyaman karena kambing tidak bersentuhan dengan kotoran dan urin. Atap kandang terbuat dari asbes. Tipe atap kandang kandang yang digunakan yaitu tipe gable. Dinding kandang terbuat dari kayu dan dibuat terbuka sehingga tidak membuat kambing mengalami stress panas.

Kambing Saburai di Kecamatan Gisting, Kota Agung, dan Sumberejo diberikan pakan berupa hijauan. Hijauan yang digunakan berupa rumput, legum seperti kaliandra, gamal, dan indigofera, dan beberapa jenis ramban seperti daun singkong, daun coklat, dan daun mangga yang diperoleh peternak di sekitar rumah atau kebun. Bahan-bahan pakan tersebut juga ada yang dijadikan silase sehingga lebih tahan lama. Ratarata pemberian pakan dilakukan dua kali sehari yaitu pada pagi dan sore hari. Pemberian minum dilakukan sekali sehari di dalam ember.

Kondisi lingkungan ternak akan mempengaruhi kondisi kesehatan ternak. Lingkungan yang sehat dan bersih akan meminimalisir pertumbuhan bibit penyakit. Pada lokasi penelitian manajemen kesehatan yang rutin dilakukan adalah pembersihan kandang dan pemberian obat cacing.

Pembersihan kandang dilakukan setiap hari. Kotoran kambing akan diambil jika peternak merasa kotoran tersebut sudah banyak. Kotoran kambing akan dipakai peternak untuk memupuk sayuran. Pemberian obat cacing dilakukan setiap 3--6 bulan sekali oleh peternak. Peternak juga memberikan obat-obatan berupa vitamin B kompleks apabila ternak menunjukkan gejalagejala sakit.

Tabel 1. Performa kambing Saburai di Kecamatan Gisting

\begin{tabular}{lcc}
\hline \multicolumn{1}{c}{ Peubah } & \multicolumn{2}{c}{ Paritas } \\
\cline { 2 - 3 } & Pertama & Kedua \\
\hline Bobot lahir & $2,66 \pm 0,45$ & $2,75 \pm 0,28$ \\
Bobot sapih hasil penimbangan (kg) & $15,03 \pm 1,21$ & $15,4 \pm 1,92$ \\
Bobot sapih terkoreksi (kg) & $20,22 \pm 0,77$ & $20,99 \pm 1,47$ \\
Koefisien keragaman (\%) & 3.81 & 7 \\
Umur induk (bulan) & $16,31 \pm 1,55$ & $25,49 \pm 1,29$ \\
Umur sapih (hari) & $118,04 \pm 2,16$ & $116,76 \pm 1,63$ \\
Jumlah kelahiran tunggal & 23 & 10 \\
Jumlah kelahiran kembar kedua & 22 & 35 \\
Jumlah kelahiran cempe jantan (ekor) & 22 & 10 \\
Jumlah kelahiran cempe betina (ekor) & 45 & 70 \\
Jumlah induk yang diamati (ekor) & 45 & 45 \\
\hline
\end{tabular}

Tabel 2. Performa kambing Saburai di Kecamatan Kota Agung Timur

\begin{tabular}{lcc}
\hline \multirow{2}{*}{ Peubah } & \multicolumn{2}{c}{ Paritas } \\
\cline { 2 - 3 } & Pertama & Kedua \\
\hline Bobot lahir & $2,98 \pm 0,29$ & $3,02 \pm 0,50$ \\
Bobot sapih hasil penimbangan (kg) & $5,54 \pm 0,73$ & $4,88 \pm 1,88$ \\
Bobot sapih terkoreksi (kg) & $10,8 \pm 0,96$ & $8,96 \pm 1,88$ \\
Koefisien keragaman (\%) & 8,89 & 20,89 \\
Umur induk (bulan) & $15,94 \pm 0,84$ & $24,98 \pm 0,94$ \\
Umur sapih (hari) & $105,94 \pm 11,25$ & $64,96 \pm 24,29$ \\
Jumlah kelahiran tunggal & 47 & 0 \\
Jumlah kelahiran kembar kedua & 0 & 47 \\
Jumlah kelahiran cempe jantan (ekor) & 24 & 13 \\
Jumlah kelahiran cempe betina (ekor) & 23 & 74 \\
Jumlah induk yang diamati (ekor) & 47 & 47 \\
\hline
\end{tabular}


Tabel 3. Performa kambing Saburai di Kecamatan Sumberejo

\begin{tabular}{lcc}
\hline \multicolumn{1}{c}{ Peubah } & \multicolumn{2}{c}{ Paritas } \\
\cline { 2 - 3 } & Pertama & Kedua \\
\hline Bobot lahir & $3,15 \pm 0,60$ & $3,03 \pm 0,39$ \\
Bobot sapih hasil penimbangan (kg) & $12,98 \pm 2,68$ & $12,64 \pm 2,54$ \\
Bobot sapih terkoreksi (kg) & $21,57 \pm 4,86$ & $14,3 \pm 2,63$ \\
Koefisien keragaman (\%) & 22,53 & 18,39 \\
Umur induk (bulan) & $16,98 \pm 2,89$ & $25,76 \pm 1,39$ \\
Umur sapih (hari) & $108,02 \pm 21,21$ & $113,24 \pm 12,06$ \\
Jumlah kelahiran tunggal & 23 & 14 \\
Jumlah kelahiran kembar kedua & 27 & 36 \\
Jumlah kelahiran cempe jantan (ekor) & 21 & 41 \\
Jumlah kelahiran cempe betina (ekor) & 52 & 35 \\
Jumlah induk yang diamati (ekor) & 50 & 50 \\
\hline
\end{tabular}

Hasil penelitian menunjukkan bahwa ratarata bobot sapih terkoreksi kambing Saburai di Kecamatan Gisting (Tabel 1) pada paritas pertama yaitu $20,22 \pm 0,77$ dan pada paritas kedua yaitu $20,99 \pm 1,47$, sedangkan pada kecamatan Kota Agung timur (Tabel 2) rata-rata bobot sapih terkoreksi kambing saburai pada paritas pertama $10,80 \pm 0,96$ dan pada paritas kedua $8,96 \pm 1,88$ dan nilai bobot sapih terkoreksi di Kecamatan Sumberejo (Tabel 3) rata--rata bobot sapih terkoreksi kambing Saburai pada paritas pertama $21,57 \pm 4,86$ dan pada paritas kedua 14,30 2,63 .

Bobot sapih terkoreksi hasil penelitian di Kecamatan Sumberejo lebih rendah dibandingkan pada penelitian Suhartanti (2017) yaitu di Kecamatan Sumberejo $(22,13 \pm 4,39$ dan $20,84 \pm 3,68)$ sedangkan pada nilai bobot sapih terkoreksi hasil penelitian pada Kecamatan Gisting lebih tinggi daripada hasil penelitian Suhartanti (2017) yaitu $16,29 \pm 4,99$ dan $14,67 \pm 4,33$. Nilai bobot sapih terkoreksi di Kecamatan Sumberejo yang lebih rendah diduga karena adanya perbedaan umur induk saat melahirkan. Umur induk saat melahirkan pada penelitian ini yaitu $17,35 \pm 1,69$ pada paritas pertama dan $28,05 \pm 1,81$ pada paritas kedua sedangkan pada penelitian Suhartanti (2017) umur induk saat melahirkan yaitu 15,58 $\pm 1,36$ pada paritas pertama dan $23,80 \pm 1,51$ pada paritas kedua. Umur induk yang lebih muda akan berpengaruh pada nilai FKUI yang lebih tinggi sehingga perhitungan nilai bobot sapih terkoreksi yang lebih tinggi.

Nilai bobot sapih terkoreksi pada Kecamatan Gisting hasil penelitian lebih tinggi dibandingkan Suhartanti (2017). Hal ini karena adanya perbedaan umur penyapihan. Umur penyapiahan di Kecamatan Gisting pada penelitian ini sebesar 93,50土9,71 dan $94,00 \pm 10,28$ sedangkan pada penelitian Suhartanti (2017) sebesar 76,18 $\pm 25,71$ dan $65,70 \pm 17,80$. Umur penyapiahan akan mempengaruhi bobot cempe. Semakin lama umur penyapihan cempe maka bobot sapih yang dihasilkan lebih tinggi karena konsumsi pakan cempe lebih banyak. Cempe dengan umur sapih yang lebih tinggi juga akan mendapatkan susu dari induk yang lebih banyak. Hal ini sesuai dengan pernyataan Maylinda (2010) yang menyatakan bahwa bobot sapih dipengaruhi oleh manajemen pemeliharaan dan produksi susu induk.

Bobot sapih atau bobot hidup umur 90 hari merupakan performa yang seringkali digunakan sebagai kriteria seleksi pada kambing. Cempe dengan bobot sapih yang tinggi dapat diprediksi memiliki bobot sapih dan laju pertumbuhan pascasapih yang tinggi pula (Sulastri, 2002).

Bobot sapih merupakan indikator kemampuan induk dalam menghasilkan susu dan kemampuan anak untuk mendapatkan susu dan mengalami pertumbuhan selama masa menyusui. Kemampuan produksi susu seekor induk sangat beragam yang dipengaruhi oleh genetik dan lingkungan. Pengaruh lingkungan yang utama berasal dari pakan yang dikonsumsi.

Bobot sapih juga dipengaruhi keragaman maternal yang merupakan bagian dari keragaman lingkungan berpengaruh terhadap performans pertumbuhan saat sapih. Keragaman lingkungan maternal sangat mempengaruhi keragaman lingkungan temporer karena induk juga disebabkan oleh keragaman lingkungan temporer yang antara lain berasal dari pakan dan kondisi lingkungan yang secara langsung berpengaruh terhadap fenotip induk. Tingginya keragaman lingkungan temporer tersebut menutup keragaman genetik total dan lingkungan permanen (Das et al., 2005).

Bobot sapih kambing Saburai yang beragam dipengaruhi oleh keragaman maternal dan lingkungan. Hal ini juga ditegaskan oleh Lu (2002) bahwa bobot sapih dipengaruhi olehgenetik, umur sapih, kesehatan, manajemen 
pemeliharaan, pakan, dan produksi susu induk. Faktor lain yang mempengaruhi tinggi rendahnya bobot sapih yaitu jenis kelamin, umur induk tipe kelahiran, dan umur sapih (Hardjosubroto, 1994), kondisi induk, jumlah dankondisi anak kambing yang dilahirkan (Sutama, 2007).

\section{Nilai Ripitabilitas Bobot Sapih Kambing Saburai}

Nilai ripitabilitas bobot sapih kambing Saburai yang diperoleh dalam penelitian ini yaitu pada Kecamatan Gisting 0,4786, Kecamatan Kota Agung Timur 0,065 dan Kecamatan Sumberejo 0,19 . Penghitungan nilai ripitabilitas bobot sapih kambing Saburai di Kecamatan Gisting tergolong dalam kategori tinggi sedangkan Kecamatan Kota Agung Timur dan Kecamatan Sumberejo tergolong rendah.

Hal ini sesuai dengan pernyataan Sulastri dan Dakhlan (2002) yang sependapat juga dengan Hardjosubroto (1994) bahwa nilai ripitabilitas dapat digolongkan dalam tiga kategori yaitu rendah apabila nilainya $0,0--0,2$; sedang apabila nilainya $0,2--0,4$; dan tinggi apabila nilainya lebih dari 0,4 .

Nilai ripitabilitas bobot sapih Kecamatan Gisting 0,4786 termasuk dalam kelas tinggi. Hal tersebut menunjukkan bahwa kemampuan induk dalam menghasilkan bobot sapih yang relatif sama pada setiap paritas termasuk kategori sedang. Berdasarkan rumus ripitabilitas, maka nilai ripitabilitas 0,4786 memiliki arti bahwa perbedaan bobot lahir anak sapi pada paritas pertama dan kedua, $48 \%$ disebabkan oleh faktor genetik dan lingkungan permanen sedangkan 52\% dipengaruhi oleh faktor lingkungan temporer.

Nilai ripitabilitas bobot sapihKecamatan Kota Agung Timur dan Kecamatan Sumberejo masing-masing yaitu 0,065 dan 0,19 termasuk dalam kelas rendah. Hal tersebut menunjukkan bahwa kemampuan induk dalam menghasilkan bobot sapih yang relatif berbeda setiap paritas.

Berdasarkan rumus ripitabilitas, maka nilai ripitabilitas 0,065 memiliki arti bahwa perbedaan bobot lahir anak kambing pada paritas pertama dan kedua, 6,5\% disebabkan oleh faktor genetik dan lingkungan permanen sedangkan 93,5\% dipengaruhi oleh faktor lingkungan temporer dan nilai ripitabilitas 0,19 memiliki arti bahwa perbedaan bobot lahir anak sapi pada paritas pertama dan kedua, 19\% disebabkan oleh faktor genetik dan lingkungan permanen sedangkan $81 \%$ dipengaruhi oleh faktor lingkungan temporer.

Menurut Sulastri (2014), kambing mulai hidup mandiri dan terlepas dari perawatan induk setelah sapih. Semakin rendahnya ketergantungan cempe terhadap pengaruh induk mengakibatkan semakin rendahnya komponen keragaman lingkungan temporer sehingga meningkatkan keragaman genetik total dan keragaman lingkungan permanen. Nilai ripitabilitas merupakan pencerminan dari sifat-sifat yang diulang setiap kali

Selama hidupnya dan berguna untuk memperkirakan produktivitas ternak tersebut pada masa mendatang (Warwick et al., 1990). Dinyatakan juga oleh Pattie dan James (1985), bahwa nilai ripitabilitas berkisar antara nol sampai satu. Nilai ripitabilitas yang tinngi menunjukkan tingginya keragaman genetik danlingkungan temporer serta rendahnya keragaman lingkungan temporer. Ripitabilitas (angka pengulangan) merupakan batas maksimum dari angka pewarisan sifat (heritabilitas).

Nilai ripitabilitas bukan suatu konstanta karena dipengaruhi oleh frekuensi gen sifat yang diestimasi. Frekuensi gen mengalami perubahan sesuai dengan kondisi populasi peternakan kambing yang selalu mengalami dinamika (perubahan) akibat adanya seleksi, perkawinan, mutasi masuk dan mutasi keluar. Berdasarkan kondisi populasi tersebut, ripitabilitas harus diestimasi secara periodik setidaknya setiap satu generasi (sekitar 3 tahun pada kambing). Ripitabilitas yang diestimasi secara periodik merupakan informasi yang handal untuk digunakan sebagai pedoman dalam pelaksanaan pemuliabiakan ternak (Warwick et al., 1990; Hardjosubroto, 1994).

\section{SIMPULAN DAN SARAN}

\section{Simpulan}

Berdasarkan hasil penelitian dan pembahasan maka dapat disimpulkan sebagai berikut :

1. nilai ripitabilitas kambing Saburai di Kecamatan Gisting sebesar 0,478 (kategori tinggi), di Kecamatan Kota Agung Timur sebesar 0,13 (kategori rendah), dan di Kecamatan Sumberejo sebesar 0,19 (kategori rendah).

2. rata-rata nilai MPPA kambing Saburai di Kecamatan Gisting sebesar 20,65 $\pm 0,05$ sedangkan di Kecamatan Kota Agung Timur sebesar 9,88 $\pm 0,01$ dan di Kecamatan Sumberejo sebesar $17,91 \pm 0,06$. Terdapat 10 ekor induk setiap Kecamatan dengan nilai MPPA tertinggi,di Kecamatan Gisting yaitu (G1, G2, G3, G4, G5, G6, G7, G8, G9, G10),di Kecamatan Kota Agung Timur ((K1, K2, K3, $\mathrm{K} 4, \mathrm{~K} 5, \mathrm{~K} 6, \mathrm{~K} 7, \mathrm{~K} 8, \mathrm{~K} 9, \mathrm{~K} 10$ ), dan di Kecamatan Sumberejo (S1, S2, S3, S4, S5, S6, S7, S8, S9, S10). 


\section{Saran}

Berdasarkan hasil penelitian ini disarankan kepada peternak Kecamatan Gisting untuk dapat mempertahankan induk dengan nilai MPPA yang tinggi untuk menghasilkan bobot sapih kambing Saburai yang tinggi serta melakukan culling pada induk-induk dengan nilai MPPA rendah, dan untuk Kecamatan Kota Agung Timur dan Sumberejo dapat diperbaiki induk dengan nilai MPPA yang tinggi untuk menghasilkan bobot sapih kambing Saburai yang tinggi serta melakukan culling pada induk-induk dengan nilai MPPA rendah.

\section{DAFTAR PUSTAKA}

Badan Pusat Statistik. 2017. Populasi Kambing menurut Provinsi Tahun 2009--2016. https//www.bps.go.id

Becker, W. A. 1992. Manual of Quantitative Genetics. Fifth Edition. Academic Enterprises . Pullman. USA.

Das, S. M., J.E.O Rege, and M. Shibre. 2005. Phenotypic and Genetic Parameters of Growth Traits of Blended Goats at Malya, Tanzania. Diakses 12 Maret 2019.

Dinas Peternakan dan Kesehatan Hewan Provinsi Lampung. 2015. Proposal Penetapan Rumpun Kambing Saburai. Dinas Peternakan dan Kesehatan Hewan Provinsi Lampung. Bandar Lampung.

Falconer, D.S. and T.F.C. Mackay. 1996. Introduction to Quantitative Genetics. Fourth Edition. Longman Group Ltd. England.

Hardjosubroto, W. 1994. Aplikasi Pemuliabiakan Ternak di Lapangan. PT Grasindo. Jakarta.

Lu, C.D. 2002. Boer Goat Production: Progress And Perspective. Vice Chancellor of Academic Affairs. University of Hawai Hilo.

Hawai. http://www.uhh.hawaii.edu/uhh/vcaa/. Diakses 15 April 2019.

Maylinda, S. 2010. Pengantar Pemuliaan Ternak. Cetakan Pertama. Universitas Brawijaya Press. Malang.

Pattie, W.A dan J.W. James. 1985. Principles of Applied Animal Breeding. Departemen of Animal Production University of Queensland. Australia.

Pemerintah Kabupaten Tangamus. 2016. LKj Pemerintah Kabupaten Tanggamus. http://www.search=lkj.tanggamus.go.id. Diakses 10 Mei 2019.

Suhartanti, T.Y. 2017. Nilai Indeks Produktivitas Induk Kambing Saburai di Kecamatan Sumberejo dan Kecamatan Gisting
Kabupaten Tanggamus. Skripsi Fakultas Pertanian, Universitas Lampung.

Sulastri. 2001. Estimasi nilai ripitabilitas dan MPPA (Most Probable Producing

Ability) induk kambing Peranakan Etawah di Unit Pelaksana Teknis Ternak Singosari, Malang, Jawa Timur. Jurnal Ilmiah Sains Teks 4(4):37.

Sulastri dan A. Dakhlan. 2002. Dasar Pemuliaan Ternak. Buku Ajar. Universitas Lampung. Bandar Lampung.

Sulastri dan D. A. Sukur. 2015. Evaluasi kinerja wilayah sumber bibit kambing Saburai di Kabupaten Tanggamus. Prosiding. Seminar Nasional Sains \& Teknologi 6:282--290.

Sulastri, Sumadi, dan W. Hardjosubroto. 2002. Estimasi parameter genetik sifat-sifat pertumbuhan kambing Peranakan Etawah di Unit Pelaksana Teknis Ternak Singosari, Malang, Jawa Timur. Agrosains 15(3): 431--442.

Sulastri, Sumadi, T. Hartatik, dan N. Ngadiyono. 2014. Performans pertumbuhan kambing Boerawa di Village Breeding Centre, Desa Dadapan, Kecamatan Sumberejo, Kabupaten Tanggamus, Provinsi Lampung. Jurnal Sains Peternakan 12(1): $1--9$.

Sulastri. 2010. Genetic potency of weaning weight of Boerawa F1, backcross 1 and backcross 2 does at Breeding Village Centre, Tanggamus Regency, Lampung Province. Proceeding of the $5^{\text {th }}$ International Seminar of Tropical Animal Production 6:556--560.

Sulastri, M. D. I. Hamdani, dan K. Adhianto. 2016. Penentuan sistem pemuliabiakan dalam populasi kambing Saburai untuk meningkatkan kinerja pertumbuhannya. Jurnal Riset Agribisnis \& Peternakan 1(1):10--21.

Sutama, I. K., I. G. M. Budiarsana, I. W. Mathius, dan E. Juarini. 1999. Pertumbuhan dan perkembangan seksual anak kambing Peranakan Etawa dari induk dengan tingkat produksi susu yang berbeda. Jurnal Ilmu Ternak dan Veteriner 4(2):95-10 .

Sutama. 2007. Introduksi Teknologi Produksi Kambing Perah Sebagai Komponen Agribisnis di Lahan Marginal di Temanggung. Laporan Hasil Penelitian. Balai Penelitian Ternak. Bogor.

Warwick, E.J., J.M. Astuti, dan W. Hardjosubroto. 1990. Pemuliaan Ternak. Gadjah Mada University Press. Yogyakarta. 